\title{
Calculating the Full Free Energy Profile for Covalent Modification of a Druggable Cysteine in Bruton's Tyrosine Kinase
}

\author{
Ernest Awoonor-Williams* and Christopher N. Rowley* \\ Department of Chemistry, Memorial University of Newfoundland, St. John's, NL, A1B 3X9, Canada. \\ Covalent Modification, Thiol-Michael Addition, Bruton's Tyrosine Kinase, Absolute Binding Free Energy, QM/MMMD
}

\begin{abstract}
Targeted Covalent Inhibitors bind to their targets both covalent and non-covalent modes, providing exceptionally high affinity and selectivity. These inhibitors have been effectively employed as inhibitors of protein kinases, with Taunton and coworkers (Nat. Chem. Biol. 2015, 11 (7), 525-531) reporting a notable example of a TCI with a cyanoacrylamide warhead that forms a covalent thioether linkage to an active-site cysteine (Cys481) of Bruton's tyrosine kinase. The specific mechanism of the binding and the relative importance of the covalent and non-covalent interactions is difficult to determine experimentally, but established simulation methods for calculating the absolute binding affinity of an inhibitor cannot describe the covalent bond forming steps. Here, an integrated approach using alchemical free energy perturbation and QM/MM molecular dynamics methods was employed to model the complete Gibbs energy profile for the covalent inhibition of BTK by a cyanoacrylamide TCI. These calculations provide a rigorous and complete absolute Gibbs energy profile of the covalent modification binding process. The mechanism is ionic, where the target cysteine is deprotonated to form a nucleophilic thiolate, which then undergoes a facile conjugate addition to the electrophilic functional group to form a bond with the non-covalently bound ligand. This model predicts that the formation of the covalent linkage makes binding $19.3 \mathrm{kcal} / \mathrm{mol}$ more exergonic than the non-covalent binding alone. Nevertheless, non-covalent interactions between the ligand and individual amino acid residues in the binding pocket of the enzyme are also essential for ligand binding, particularly, van der Waals dispersion forces that have a larger contribution to the binding energy than the covalent component in absolute terms. This model also shows that the mechanism of covalent modification of a protein occurs through a complex series of steps and that entropy, conformational flexibility, non-covalent interactions, and the formation of covalent linkage are all significant factors in the ultimate binding affinity of a covalent drug to its target.
\end{abstract}

\section{Introduction}

A number of new covalent-modifier drugs have been developed recently, which are notable for their high affinity and selectivity. ${ }^{1,2,3} \mathrm{To}$ date, there are over $40 \mathrm{FDA}$-approved covalent drugs. ${ }^{4}$ These drugs have been particularly successful for targeting specific members of the protein kinase family, ${ }^{S-7}$ including afatinib and ibrutinib. Afatinib is used in the treatment of metastatic non-small cell lung cancer, ${ }^{8}$ and ibrutinib is used for treating B cell cancers like chronic lymphocytic leukemia. ${ }^{9}$ Covalent drugs form a chemical bond with their targets and tend to be more therapeutically potent than their conventional non-covalent drug binding counterparts. Also, covalent drugs offer the unique benefits of prolonged duration of therapeutic action, improved efficacy, and high target selectivity. ${ }^{10}$

The standard mechanism of the covalent modification of a protein involves the reaction of a nucleophilic moiety of a target protein with an electrophilic functional group of the drug (a.k.a., the "warhead"). Through deprotonation of the side chain of nucleophilic amino acids, cysteine, serine, and lysine can become strong nucleophiles (i.e., cysteine: $-\mathrm{S}^{-}$, serine: $-\mathrm{O}^{-}$, lysine: $-\mathrm{NH}_{2}$ ), capable of undergoing a conjugate addition with an electrophilic functional group of a drug. ${ }^{11}$ In particular, cysteines have emerged as popular targets because of the relatively modest solution $\mathrm{pK}_{\mathrm{a}}$ of its thiol side chain $(\sim 8.6){ }^{12}$ which enables deprotonation of the neutral thiol group to the negatively charged thiolate form. This property of cysteine coupled with its presence in and around functionally important sites has been exploited in designing targeted covalent inhibitors of the protein kinase family of enzymes ${ }^{13,14}$ - one of the most important drug targets of the $21^{\text {st }}$ century. ${ }^{15}$ Significantly, all the FDA-approved covalent kinase inhibitors bind through the formation of a thioether linkage with a non-catalytic cysteine residue in the catalytic domain of kinases. ${ }^{16}$

There are a broad range of chemical motifs in existing drugs ${ }^{17}$ that can covalently modify nucleophilic functional groups in proteins. Among these, $\alpha, \beta$-unsaturated carbonyl compounds, ${ }^{18}$ and acrylamides in particular, dominate the current pharmacopeia of covalent inhibitors. These acrylamide-based covalent inhibitors undergo a thiol-Michael addition reaction ${ }^{19}$ with a non-catalytic cysteine residue of a desired target (Scheme 1(a)). The acidity of the cysteine thiol side chain is a prime determinant for its reactivity towards an electrophilic warhead of a covalent inhibitor or drug. ${ }^{20}$ The first step of the covalent inhibition mechanism is the formation of a non-covalent protein-drug complex (Scheme $1(\mathrm{~b})$ ), which is characterized by an equilibrium inhibition constant $\left(\mathrm{K}_{\mathrm{I}}\right)$. This positions the electrophilic warhead of the drug where it can undergo a reaction with the nucleophilic amino acid residue of the target enzyme. Following this, the covalent bond is formed between the drug and the enzyme target, with the adduct formation described by the inactivation rate constant $\left(k_{\text {inact }}\right)$, Scheme $1(b)$.

Scheme 1. (a) Thiol-Michael addition reaction showing the covalent modification of cysteine residue in enzyme target by 
acrylamide moiety (in red). (b) Mechanism of Covalent Inhibition of Enzyme (E) by inhibitor (I). E - I denotes the equilibrium non-covalent complex characterized by $\mathrm{K}_{\mathrm{I}}$, while $\mathrm{E}-\mathrm{I}$ signifies the covalent adduct upon the chemical reaction step ( $\left.k_{\text {inact }}\right)$.

(a)

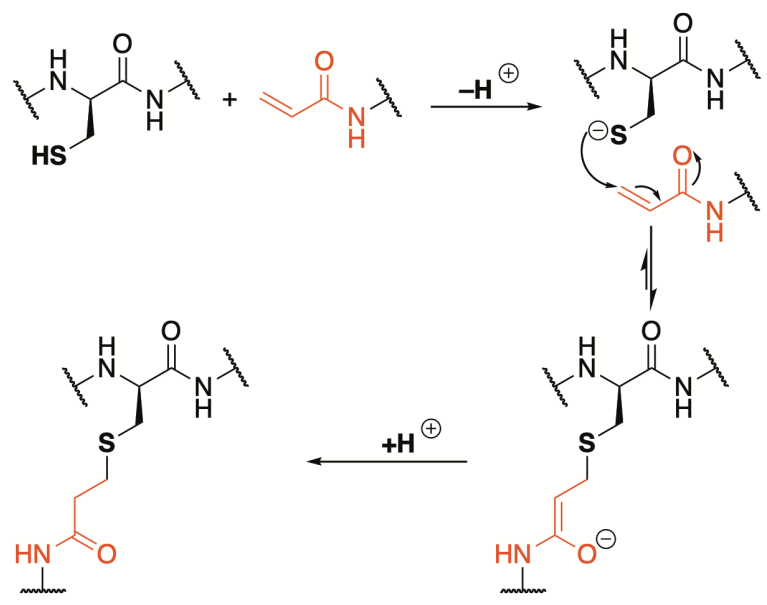

(b)

$$
\mathrm{E}+\mathrm{I} \stackrel{K_{l}}{\rightleftharpoons} \mathrm{E} \cdot \mathrm{I} \stackrel{K_{\text {inact }}}{\rightleftarrows} \mathrm{E}-\mathrm{I}
$$

Although covalent binding has traditionally been thought of as being irreversible, recent work by Taunton and coworkers have shown that thiol-Michael additions of electrophiles can be tuned to react with target cysteines in a reversible manner. ${ }^{21-23}$ In their recent work, an established kinase-binding scaffold was substituted with cyanoacrylamide electrophilic warheads (Figure 1), yielding compounds that form a covalent linkage to Cys481 of Bruton's Tyrosine Kinase (BTK), but dissociate on timescales of several hours to days. ${ }^{23}$ BTK is a clinically-validated target for treating B cell malignancies. These covalent-but-reversible targeted covalent inhibitors could provide the advantages of high affinity and long residence times that covalent inhibitors provide, but with reduced potential for off-target modification of proteins that have been implicated in toxicity and immunogenicity.

Modeling the mechanism of covalent modification of a druggable residue in a target requires the use of high-level multiscale simulation methods to account for the non-covalent and covalent binding steps. Free energy perturbation molecular dynamics (FEP/MD) can provide accurate estimates of the binding affinity, selectivity, and specificity of ligands for druggable enzyme targets. ${ }^{24-32}$ Quantum mechan$\mathrm{ical} /$ molecular mechanical (QM/MM) methods can be used to describe the potential energy surfaces and reaction thermodynamics of the steps in the covalent reaction mechanism. ${ }^{33,34}$ In particular, the chemical bond formed during the binding step of the covalent modification process can only be described using quantum chemical methods. In combination, these methods can provide a complete model for the relative free energies of both the non-covalent and covalent components of the binding of these drug molecules to their enzyme targets.

Although a number of studies have reported on the kinetics of cysteine-targeted thiol-Michael additions, ${ }^{35-37}$ a complete atomistic model describing all the steps of the mechanism is still lacking. Traditional FEP calculations are only able to describe the non-covalent binding step of the chemical reaction, but not the chemical reaction steps that is at the heart of covalent modification. Modeling covalent modification will require calculating the total covalent and non-covalent binding energies and evaluating the full free energy profile of the chemical reaction. To address this issue, we employ alchemical free energy perturbation and QM/MM molecular dynamics methods to model all the steps in the covalent modification process of a druggable cysteine in BTK. Our model system consists of a proteinligand complex of BTK with a t-butyl cyanoacrylamide ligand, bearing a piperidine linker and pyrazolopyrimidine scaffold, Figure 1(a). A high-resolution X-ray crystallographic structure has been reported for this model system (PDB ID: 4YHF). The cyanoacrylamide ligand is a highly potent and selective reversible covalent inhibitor of $\mathrm{BTK},{ }^{23}$ and undergoes a thiol-Michael addition with Cys 481 of BTK, Figure 1(b).

(a)
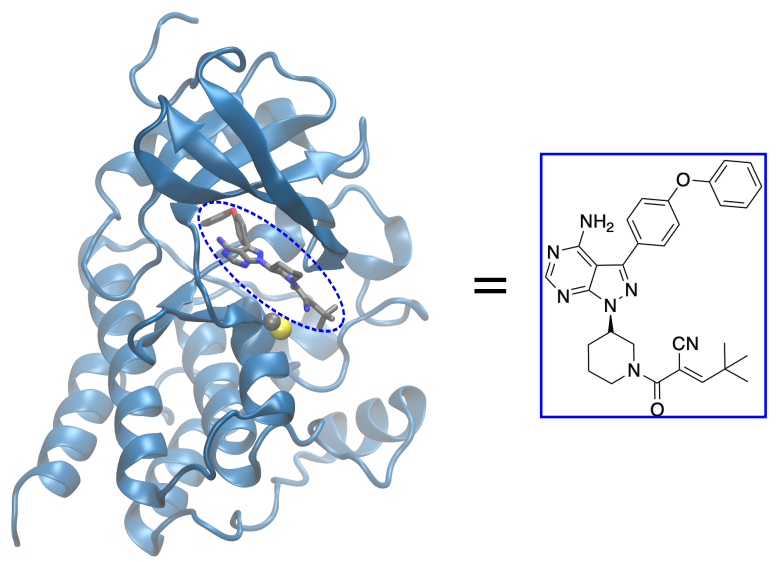

(b)
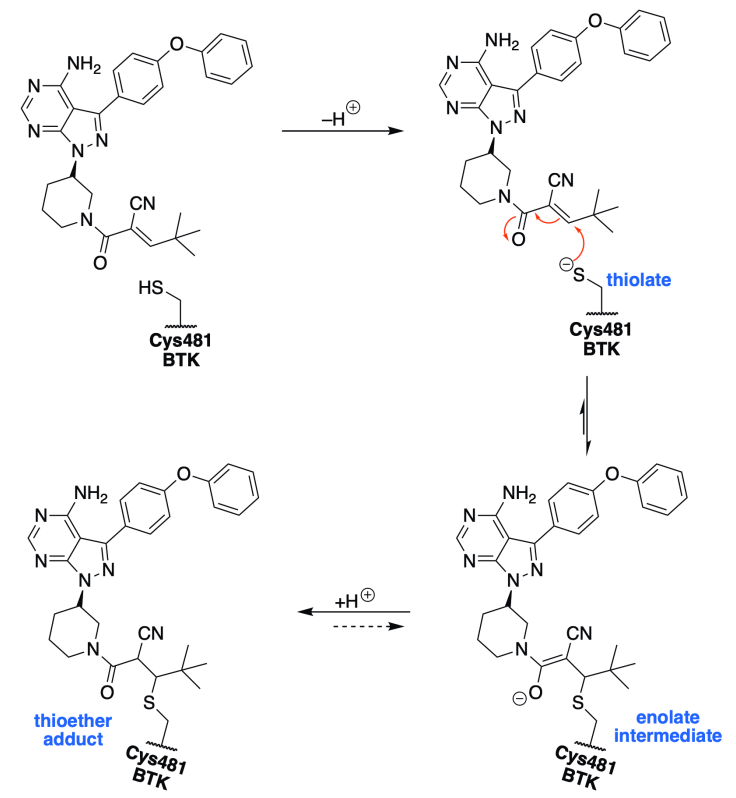

Figure 1. (a) X-ray cocrystal structure of BTK in complex with a tbutyl cyanoacrylamide ligand (PDB ID: 4YHF). The chemical structure of the t-butyl cyanoacrylamide ligand is highlighted. (b) Reaction mechanism showing the steps involved in the covalent modification of Cys 481 of BTK by t-butyl cyanoacrylamide ligand.

To quantify and describe the energetic determinants of all the steps involved in the cysteine-targeting thiol-Michael addition reaction, we performed $\mathrm{FEP} / \mathrm{MD}$ and $\mathrm{QM} / \mathrm{MM} \mathrm{MD}$ simulations to calculate a rigorous, complete binding energy profile of the cyanoacrylamide ligand binding to BTK in explicit aqueous solvent. A FEP/MD procedure $^{38}$ was adopted to compute the absolute non-covalent binding free energy of the ligand to the receptor kinase. The potential of 
mean force (PMF) for the chemical addition of the electrophilic cyanoacrylamide warhead of the ligand to Cys481 of BTK was calculated using QM/MM MD umbrella sampling simulations using the same simulation cell, where the protein-ligand complex is immersed in an explicit aqueous solvent. The ONIOM QM/MM methodology $^{39}$ was used to compute the energy of the final covalent adduct. The combined computational methodology adopted in our study allows for an in-depth thermodynamic dissection of the molecular determinants governing the mechanism of cysteine thiol covalent modification by a targeted covalent inhibitor.

\section{Theory and Methods}

Ligand-Protein System Setup: The initial structure of BTK complexed with t-butyl cyanoacrylamide ligand was taken from PDB entry $4 \mathrm{YHF} .{ }^{23}$ Model systems of the X-ray crystallographic structure of BTK were constructed with Cys481 in both the protonated thiol ($\mathrm{SH})$ and deprotonated thiolate $\left(-\mathrm{S}^{-}\right)$states. All crystallographically resolved water molecules in the structure were retained in the model systems. Molecular dynamics simulations were performed in an explicit aqueous solvent using the TIP $3 \mathrm{P}^{40}$ water model. The GAAMP method $^{41}$ and CHARMM General Force Field (CGenFF) ${ }^{42}$ were used to obtain the ligand charges and molecular mechanical parameters, respectively. CHARMM36 all-atom protein force field ${ }^{43}$ was used to model the protein. Our previous biomolecular simulation studies have shown that the CHARMM36 force field provides the most accurate prediction of the experimental hydration structure of model cysteine thiolates, ${ }^{44}$ as well as cysteine $\mathrm{pK}_{\mathrm{a}}$ 's in proteins. ${ }^{45}$

The initial protein-ligand complex was solvated in a simulation cell with dimensions of $72 \times 72 \times 80 \AA^{3}$. Sodium ions were added to neutralize the system. All MD simulations of the protein-ligand complex were performed using NAMD $2.13^{46}$ under periodic boundary conditions. A constant temperature of $298.15 \mathrm{~K}$ and pressure of 1 atm was applied to the system using the Langevin dynamics and Langevin piston method, respectively. A Langevin damping coefficient of $1 \mathrm{ps}^{-1}$ was used for propagating dynamics and a timestep of $2 \mathrm{fs}$ was used in all the molecular dynamics simulations. Long range electrostatics interactions were treated using the particle mesh Ewald (PME) method. ${ }^{47,48}$ A cutoff distance of $12.0 \AA$ was applied to Lennard-Jones interactions. A smoothing function was applied from 10 to $12 \AA$ to smoothly truncate van der Waals forces at the cutoff distance. The SHAKE algorithm ${ }^{49}$ was applied to constrain covalent bonds involving hydrogen atoms. A series of minimization and equilibration MD simulations were performed on the model system under specific conditions chosen to match experiment (see Supporting Information). The coordinates of the equilibrated protein-ligand complex were used as the starting structure for the absolute binding free energy calculations.

Absolute Binding Free Energy Calculations: To calculate the absolute non-covalent binding free energy of t-butyl cyanoacrylamide ligand to BTK, we applied alchemical free energy perturbation $/ \lambda$ exchange molecular dynamics (FEP/ $\lambda$-REMD) and umbrella sampling/replica-exchange molecular dynamics (US/REMD) methods with restraining potentials using the double decoupling protocol developed by Roux and coworkers. ${ }^{38}$ This method provides a methodical step-by-step formulation for computing absolute protein-ligand non-covalent binding free energies ${ }^{50-52}$ and allows for the inclusion of explicit solvent, conformational entropy, and flexibility of both the ligand and the receptor. The alchemical FEP/ $\lambda$-REMD and US/REMD simulation techniques have achieved good accuracies with experimentally measured inhibitory potencies for the binding affinities of small molecule ligands to receptor tyrosine kinases. ${ }^{24-26}$ The approach relies on a series of sequential equilibrium simulations that follow a step-by-step process of the ligand binding to the receptor. The resulting binding energy contributions include the loss of conformational and orientational entropy upon binding, as well as the non-covalent binding interaction energies such as electrostatic, dispersion, and repulsive forces following the binding event, Figure 2 .

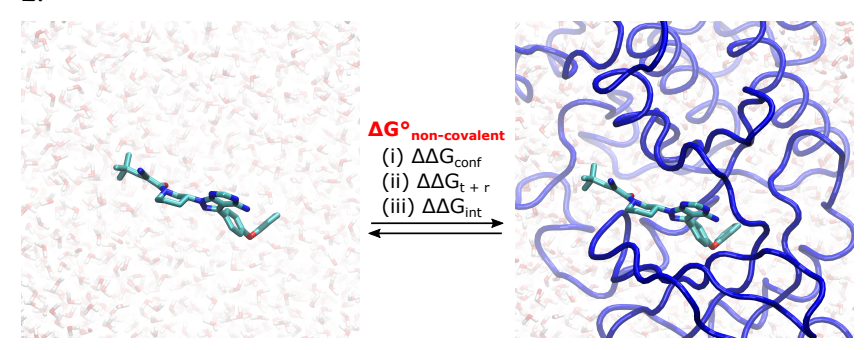

Figure 2. Structure of cyanoacrylamide ligand in bulk solution and in BTK binding site. The absolute non-covalent ligand binding energy $\left(\Delta G_{\text {non-covalent }}^{\text {o }}\right)$ is the total free energy of transferring the ligand from aqueous solvent to the protein binding site. The binding energy is derived from separate energy contributions consisting of conformational (i, $\Delta \Delta \mathbf{G}_{\text {conf }}$ ), translational and rotational (ii, $\Delta \Delta \mathbf{G}_{\mathrm{t}+\mathrm{r}}$ ), and interaction (iii, $\Delta \Delta \mathbf{G}_{\mathrm{int}}$ ) free energies.

In this scheme, the absolute non-covalent binding free energy $\left(\Delta \mathrm{G}_{\text {non-covalent }}^{\mathrm{o}}\right)$ of transferring a ligand from bulk solvent (bulk) to protein binding site (site) can be expressed as: ${ }^{25}$

$$
\begin{aligned}
\Delta G_{\text {non-covalent }}^{\text {o }}= & \Delta \Delta G_{\text {conf }}^{\text {bulk } \rightarrow \text { site }}+\Delta \Delta G_{t+r}^{\text {bulk } \rightarrow \text { site }} \\
& +\Delta \Delta G_{\text {int }}^{\text {bulk } \rightarrow \text { site }}
\end{aligned}
$$

where $\Delta \Delta G_{\text {conf }}^{\text {bulk } \rightarrow \text { site }}$ is the free energy cost associated with the loss of conformational degrees of freedom of the ligand upon binding, $\Delta \Delta \mathrm{G}_{t+r}^{\text {bulk } \rightarrow \text { site }}$ is the free energy cost associated with the loss of translational and rotational entropy of the ligand accompanying binding, and $\Delta \Delta G_{\text {int }}^{\text {bulk } \rightarrow \text { site }}$ is the non-covalent interaction energy that results from the intermolecular interactions between the ligand and its environment following the binding event. All the free energy terms that contribute to the binding energy in Eqn. (1) can be further separated into components in bulk solvent and in the protein binding site.

The free energy cost of restricting the ligand to its bound conformation $\left(\Delta \Delta G_{\text {conf }}^{\text {bulk } \rightarrow \text { site }}\right)$ is calculated as the difference of the conformational-restraining energy in the bulk solvent and in the binding site.

$$
\Delta \Delta G_{\text {conf }}^{\text {bulk } \rightarrow \text { site }}=\Delta G_{\text {conf }}^{\text {bulk }}-\Delta G_{\text {conf }}^{\text {site }}
$$

These terms correspond to the free energy contributions associated with applying and releasing conformational restraints of the ligand in bulk solution and in the binding site relative to a reference conformation. US/REMD simulations were used to obtain the conformational free energy of the ligand upon binding. These simulations were carried out by computing the potential of mean force (PMF) of the ligand as a function of the root-mean-square deviation (RMSD) relative to its bound state conformation both in bulk solvent and in the protein binding site. The force constant for all RMSD restraints used in the simulations was $50 \mathrm{kcal} / \mathrm{mol} \cdot \AA^{2}$. The average 
equilibrated conformation of the ligand-bound BTK structure was used as the reference structure for the RMSD restraint. The US/REMD simulations consisted of eight replicas centered on RMSD offsets increasing from $0.0-3.5 \AA$ in increments of $0.5 \AA$. Each replica window was sampled for $20 \mathrm{~ns}$, totaling $160 \mathrm{~ns}$ of sampling. The simulations were performed in triplicate, resulting in an aggregate simulation time of $480 \mathrm{~ns}$. The conformational free energies of the ligand in bulk solvent $\left(\Delta G_{\text {conf }}^{\text {bulk }}\right)$ and in the binding site $\left(\Delta G_{\text {conf }}^{\text {site }}\right)$ were calculated from the US/REMD data collected using the weighted histogram analysis method (WHAM). ${ }^{53}$

The translational and rotational degrees of freedom of the ligand upon binding is given by:

$$
\begin{gathered}
\Delta \Delta G_{t+r}^{\text {bulk } \rightarrow \text { site }}=\left[-k_{B} T \ln \left(F_{t} C^{\circ}\right)-\Delta G_{t}^{\text {site }}\right]+ \\
{\left[-k_{B} T \ln \left(F_{r}\right)-\Delta G_{r}^{\text {site }}\right]}
\end{gathered}
$$

where $F_{t}$ and $F_{r}$ denote the translational and rotational factors that are calculated numerically to estimate the position and orientation of the bound ligand (see Supporting Information).$^{38} C^{\circ}$ is the standard reference concentration of $1 \mathrm{~mol} / \mathrm{L}$ or $1 / 1661 \AA^{-3}$ and $\mathrm{T}$ is the absolute temperature in Kelvin. The relative position and orientation of the bound ligand in the complex was described using six internal coordinates; one distance, two angles, and three dihedrals (see Supporting Information). These values were calculated from the average of an unrestrained simulation. The force constant for the distance was set to $10 \mathrm{kcal} / \mathrm{mol} . \AA^{2}$, while those of the angles and dihedrals were set to $0.1 \mathrm{kcal} / \mathrm{mol}$.degrees ${ }^{2}$. The Gibbs energy associated with imposing each restraint was calculated using thermodynamic integration in the colvars module of NAMD. The free energy contribution due to the translational and rotational restraints on the ligand in the binding site $\left(\Delta G_{t}^{\text {site }}\right.$ and $\left.\Delta G_{r}^{\text {site }}\right)$ were then determined by integrating the free energy gradient along the connecting path. The simulation length was $67.2 \mathrm{~ns}$ for an independent run. The reported free energies are the averages three independent replicates and the uncertainty of this average is estimated by the standard deviation of these three replicates.

The interaction free energy term $\left(\Delta \Delta G_{\text {int }}^{\text {bulk } \rightarrow \text { site }}\right)$ is divided into electrostatic, dispersive, and repulsive contributions, Eqn. (4).

$$
\Delta \Delta G_{\text {int }}^{\text {bulk } \rightarrow \text { site }}=\Delta \Delta G_{\text {elec }}+\Delta \Delta G_{\text {dis }}+\Delta \Delta G_{\text {rep }}
$$

where $\Delta \Delta G_{\text {elec }}=\Delta G_{\text {elec }}^{\text {site }}-\Delta G_{\text {elec }}^{\text {bulk }}, \Delta \Delta G_{\text {dis }}=\Delta G_{\text {dis }}^{\text {site }}-\Delta G_{\text {dis }}^{\text {bulk }}$, and $\Delta \Delta G_{\text {rep }}=\Delta G_{\text {rep }}^{\text {site }}-\Delta G_{\text {rep }}^{\text {bulk }}$. These terms describe the electrostatic, dispersive, and repulsive interactions, respectively, of removing the ligand from bulk solvent and inserting it into the binding site. The dispersive and repulsive components of the free energies were obtained from the 6-12 Lennard-Jones potential using the WeeksChandler-Anderson $^{54}$ decoupling scheme. ${ }^{55}$ Alchemical FEP $/ \lambda$ REMD simulations, staged by three thermodynamic coupling paraments $\left(\lambda_{\text {elec }}, \lambda_{\text {disp }}, \lambda_{\text {rep }}\right)$ were applied to compute the ligand interaction free energies in bulk solvent and in the protein binding site. A total number of 36 replicas $\left(12 \lambda_{\text {elec }}, 12 \lambda_{\text {dis }}, 12 \lambda_{\text {rep }}\right)$ were used and the simulation length for each replica window was $20 \mathrm{~ns}$, totaling $720 \mathrm{~ns}$. The simulations were performed in triplicate, yielding a total simulation time of $2.16 \mu \mathrm{s}$. These simulations provided the interaction free energies, separated into their electrostatic, dispersive, and repulsive components for the ligand in bulk solution $\left(\Delta G_{\text {elec }}^{\text {bulk, }}\right.$, $\left.\Delta G_{\text {dis }}^{\text {bulk }}, \Delta G_{\text {rep }}^{\text {bulk }}\right)$ and in the binding site $\left(\Delta G_{\text {elec }}^{\text {site }}, \Delta G_{\text {dis }}^{\text {site }}, \Delta G_{\text {rep }}^{\text {site }}\right)$.

Potential of Mean Force Calculations: We used hybrid QM/MM MD umbrella sampling simulations to calculate the PMF for the addition reaction of the cyanoacrylamide ligand to the thiolate state of Cys481 of BTK. The initial structure was taken from the final trajectory of the FEP/ $\lambda$-REMD simulation. Hybrid QM/MM MD simulations were performed using the $\mathrm{QM} / \mathrm{MM}$ features of NAMD $2.13^{56}$ interfaced to ORCA 4.1.1 $1^{57,58}$ as the QM package. The parameters for the cyanoacrylamide ligand were the same as those used for the MD simulation and were obtained from the GAAMP method. ${ }^{41}$ The CHARMM36 all-atom force field was used to describe the protein and TIP3P water model for the explicit solvent water molecules. The QM region consisted of the t-butyl cyanoacrylamide warhead with the piperidine linker of the ligand and the thiolate side chain of Cys481 in the protein, Figure 3. This QM region includes 39 atoms. The remaining 100,870 atoms of the model system were included in the $\mathrm{MM}$ region. $\mathrm{QM} / \mathrm{MM}$ boundary region was treated by using the electronic embedding scheme ${ }^{59}$ and hydrogen link atoms were used to cap QM regions containing QM-MM bonds.

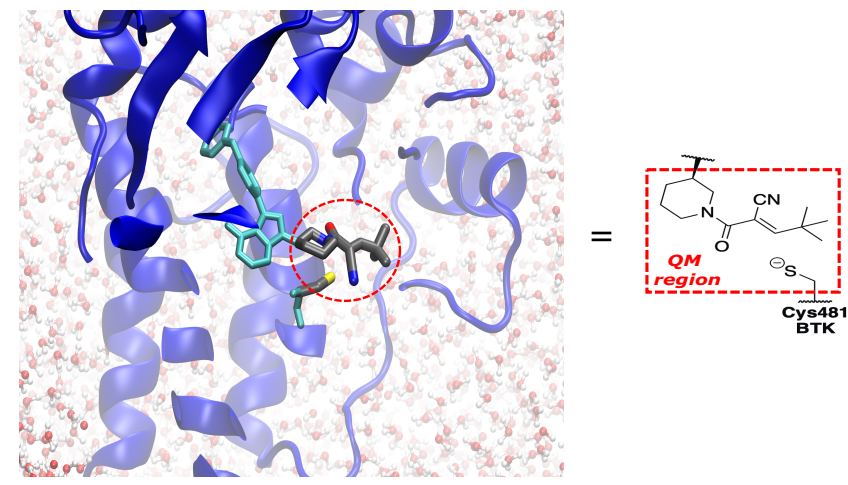

Figure 3. The $\mathrm{QM}$ region defined in our hybrid $\mathrm{QM} / \mathrm{MM} \mathrm{MD}$ calculations for the protein-ligand complex. This region consists of a piperidine linker with the electrophilic cyanoacrylamide warhead of the ligand and the thiolate side chain of Cys481 of BTK.

In order to ensure a stable $\mathrm{QM} / \mathrm{MM}$ simulation system for the PMF calculations, a series of steps involving QM-based minimization, geometry optimization, and equilibration were performed for the QM and $\mathrm{MM}$ regions. The $\mathrm{QM}$ region was treated by the $\omega \mathrm{B} 97 \mathrm{X}-\mathrm{D} 3$ functional ${ }^{60}$ with the def2-TZVP basis set. Grimme's D3 dispersion correction using Becke-Johnson damping function ${ }^{61}$ was used for the QM calculations. The $\omega$ B97X-D3 functional performs well for modeling covalent modification of thiols, ${ }^{34}$ yielding results that are in close agreement with high level $a b$ initio $\operatorname{CCSD}(\mathrm{T})$ calculations, where many popular QM methods fail. ${ }^{62}$ The hybrid QM/MM simulation system was subjected to 100 steps of energy minimization, followed by 20 ps equilibration run in the NpT ensemble with temperature maintained at $300 \mathrm{~K}$ (using a Langevin thermostat) and pressure at $1 \mathrm{~atm}$ (using a Langevin piston barostat).

The QM/MM PMF was calculated for the interval where the covalent bond is formed between $\mathrm{C}_{\beta}$ of the cyanoacrylamide group of the ligand and the thiolate $S$ atom of Cys 481 of BTK. This was performed using $\mathrm{QM} / \mathrm{MM} \mathrm{MD}$ umbrella sampling simulations for the interval $\mathrm{r}=[1.7,4.5] \AA$ where the $\mathrm{C}_{\beta}-\mathrm{S}$ bond is formed. The windows for the umbrella sampling simulations were separated by $0.1 \AA$ and a spring constant of $100 \mathrm{kcal} / \mathrm{mol} \cdot \AA^{2}$ was used for the harmonic 
restraint. For each window, the simulation length was $150 \mathrm{ps}$, with the first 5 ps discarded for equilibration. The PMF of the $\mathrm{C}_{\beta}-\mathrm{S}$ coordinate was calculated from the umbrella-sampling time series using WHAM, with the statistical uncertainties in free energies determined by bootstrap error analysis.

QM/MM Calculations using ONIOM Method: The end point of the PMF for the Cys 481 thiolate addition to $\mathrm{C}_{\beta}$ of the cyanoacrylamide ligand yields the enolate intermediate complex. In order to attain the final product of the chemical reaction (i.e., thioether adduct), the $\alpha$-carbon of the enolate intermediate must be protonated, Scheme 2. We performed ONIOM ${ }^{39} \mathrm{QM} / \mathrm{MM}$ calculations to compute the energy of the final thioether adduct. The ONIOM calculations were performed using Gaussian $16 .^{63}$ The final protein and ligand coordinates from the $\mathrm{QM} / \mathrm{MM} \mathrm{MD}$ equilibration simulation were used as the starting structure for the ONIOM QM/MM optimizations.

Scheme 2. Reaction scheme showing the protonation step required for the conversion of ligand-protein enolate intermediate complex to the thioether adduct.
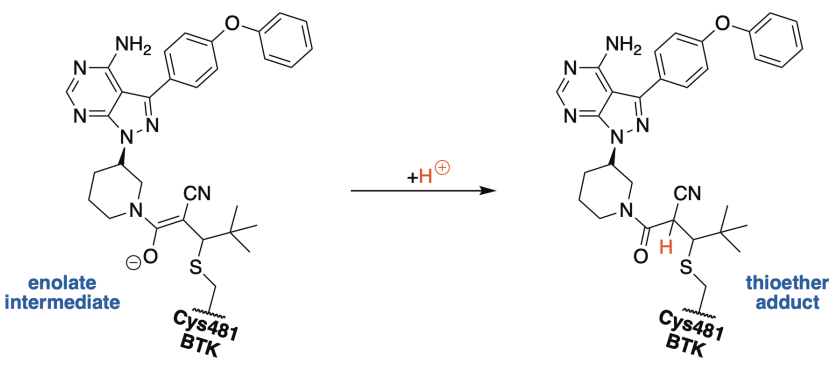

In our ONIOM model, the ligand-protein complex is divided into two regions (a.k.a., "layers"): (1) high-level DFT region, and (2) low-level molecular mechanical region. The high-level region was treated using the $\omega$ B97X-D functional with the def2-TZVP basis set, while the low-level region was treated using the Amber molecular mechanical force field. The high-level layer primarily consisted of the t-butyl cyanoacrylamide warhead with the piperidine linker of the ligand and Cys481 thiolate side chain of BTK, Figure 3. The remaining ligand and protein components were included in the lowlevel layer. In total, the high-level layer included 40 atoms, while the low-level layer of the ONIOM model was made up of 4388 atoms. $\mathrm{MM}$ charges and parameters used in the ONIOM calculations were the same as those used for the MD simulation. These models do not include explicit solvent water molecules.

The initial protein-ligand complexes were geometry optimized using the ONIOM ( $\omega$ B97X-D/def2-TZVP: AMBER) level of theory within a mechanical embedding formalism. Frequency analysis was performed on the optimized structures using the same level of theory to verify that the optimized structures were minima and to estimate the thermal correction to the Gibbs energy.

\section{Results and Discussion}

The complete binding free energy profile of the targeted covalent inhibitor to BTK was calculated using advanced molecular simulation methods and high-level QM/MM methods. These combined computational methods allowed us to model the binding of the inhibitor to BTK in a comprehensive way, through the calculation of both non-covalent and covalent binding free energy terms (i.e., $\Delta \mathrm{G}_{\text {non-covalent }}^{\mathrm{o}}$ and $\left.\Delta \mathrm{G}_{\text {covalent }}^{\mathrm{o}}\right)$. The inhibitor is a t-butyl cyanoacrylamide ligand developed by Taunton and coworkers, ${ }^{23}$ consisting of a piperidine linker and pyrazolopyrimidine scaffold (Figure $1(\mathrm{a})$ ). The complete calculation of the binding free energy of the covalent modification mechanism required the calculation of three individual components:

1. Deprotonation of the cysteine thiol side chain to form the reactive thiolate state of the protein $\left(\Delta \mathrm{G}_{\text {deprot. }}^{\circ}\right)$.

2. Non-covalent binding of the ligand to the protein $\left(\Delta \mathrm{G}^{\circ}\right.$ noncovalent).

3. Covalent bonding between the electrophilic warhead of the ligand and cysteine thiolate of the protein to form the thioether covalent adduct $\left(\Delta \mathrm{G}^{\circ}\right.$ covalent $)$.

The sum of the of these energies provides the total absolute binding energy of the ligand to its target,

$$
\begin{gathered}
\Delta \mathrm{G}_{\text {binding }}^{\circ}=\Delta \mathrm{G}_{\text {deprot. }}^{\circ}+\Delta \mathrm{G}_{\text {non-covalent }}^{\circ} \\
+\Delta \mathrm{G}_{\text {covalent }}^{\circ}
\end{gathered}
$$

\section{Deprotonation of Cys 481 of BTK}

The first step in the reaction involves the deprotonation of the thiol side chain of Cys481 in BTK to the nucleophilic thiolate form. We estimated the deprotonation Gibbs energy of Cys481 in BTK from its computed $\mathrm{pK}_{\mathrm{a}}$. The $\mathrm{pK}_{\mathrm{a}}$ of Cys 481 in BTK was computed using constant-pH molecular dynamics (see Supporting Information). Importantly, constant-pH molecular dynamics is capable of accurately calculating the probability of deprotonating the cysteine residue within the target protein, while also accounting for $\mathrm{pH}$-induced conformational changes and inter-residue interactions. Using this method, the $\mathrm{pK}_{\mathrm{a}}$ of Cys481 in BTK is calculated to be $9.4 \pm 0.2$, which corresponds to a deprotonation Gibbs energy $\left(\Delta \mathrm{G}^{\circ}{ }_{\text {deprot }}\right)$ of $1.0 \pm 0.2 \mathrm{kcal} / \mathrm{mol}$. This indicates that the deprotonation of the cysteine thiol group of Cys481 in BTK presents a modest free energy barrier to the covalent modification process.

Non-covalent Binding Free Energy Contribution. The standardstate non-covalent binding free energy of the cyanoacrylamide ligand to BTK was computed using the alchemical free energy protocol of Roux and coworkers. ${ }^{38}$ This simulation protocol yields the absolute non-covalent binding free energy $\left(\Delta G^{\circ}\right.$ non-covalent $)$ divided into a series of thermodynamic contributions: the loss of conformational flexibility, restriction of translational and rotational freedom, and the electrostatic, dispersion, and repulsive components of the proteinligand intermolecular interactions. Table 1 summarizes the results of the various contributions to the binding free energy of the ligand to BTK. These results indicate that the ligand has significant affinity for BTK through non-covalent interactions alone $\left(\Delta \mathrm{G}^{\circ}\right.$ non-covalent $=-11.4$ $\pm 1.4 \mathrm{kcal} / \mathrm{mol})$.

Table 1. Summary of Absolute Non-Covalent Binding Free Energy $\left(\Delta G_{\text {non-covalent }}^{\text {o }}\right.$ in $\left.\mathrm{kcal} / \mathrm{mol}\right)$ calculations of ligand to $B T K$.

\begin{tabular}{|c|c|}
\hline bulk $\rightarrow$ site & BTK $\left(\right.$ Cys $\left.^{\text {481 }}-\mathbf{S}^{-}\right)$ \\
\hline$\Delta \Delta G_{\text {conf }}$ & $4.4 \pm 0.3$ \\
\hline$\Delta \Delta G_{t+r}$ & $15.3 \pm 0.2$ \\
\hline
\end{tabular}




\begin{tabular}{|c|c|}
\hline$\Delta \Delta G_{\text {elec }}$ & $-5.9 \pm 0.1$ \\
\hline$\Delta \Delta G_{\text {dis }}$ & $-31.9 \pm 0.2$ \\
\hline$\Delta \Delta G_{\text {rep }}$ & $6.7 \pm 1.3$ \\
\hline$\Delta \Delta \mathrm{G}_{\text {int }}$ & $-31.1 \pm 1.4$ \\
\hline$\Delta \mathrm{G}_{\text {non-covalent }}^{\mathrm{o}}$ & $-11.4 \pm 1.4$ \\
\hline
\end{tabular}

The absolute non-covalent binding free energy of the ligand to BTK was also calculated using the GROMACS molecular dynamics software package ${ }^{64}$ with the CHARMM36 and CGenFF force fields, following the protocol reported by Aldeghi et al. ${ }^{29}$ This approach uses an alternative alchemical thermodynamic cycle to compute absolute binding free energies, which provides an independent check on our calculated binding free energy results. The calculated binding free energy of the ligand to BTK using this approach (Aldeghi et alprotocol: $\Delta \mathrm{G}_{\text {non-covalent }}^{\mathrm{o}}=-11.3 \pm 1.4 \mathrm{kcal} / \mathrm{mol}$ ) was found to be in excellent agreement with the binding energy reported in our study $\left(\Delta \mathrm{G}_{\text {non-covalent }}^{\mathrm{o}}=-11.4 \pm 1.4 \mathrm{kcal} / \mathrm{mol}\right.$; Table 1$)$. Furthermore, the calculated binding free energy result is in good agreement with experimental binding affinity measurements of a closely-related inhibitor, which has a methylpyrrolidine linker in place of the piperidine linker present in our model cyanoacrylamide ligand. ${ }^{23}$ The experimental inhibitory constant $\left(\mathrm{K}_{\mathrm{i}}\right)$ of this similar binding inhibitor is $5.2 \mathrm{~nm},{ }^{23}$ corresponding to a $\Delta \mathrm{G}_{\text {exptl. }}^{\mathrm{o}}$ value of $-11.30 \mathrm{kcal} / \mathrm{mol}$. This suggests that our computed non-covalent binding energies predict the strength of non-covalent binding interactions of these ligands well. The non-covalent binding energy of the ligand to the thiol form of Cys481 of BTK was also computed (see Supporting Information).

\section{Conformational Energies}

The free energy contribution arising from the loss of conformational degrees of freedom of the ligand upon binding $\left(\Delta \Delta G_{\text {conf }}^{\text {bulk } \rightarrow \text { site }}\right)$ is $4.4 \mathrm{kcal} / \mathrm{mol}$, Table 1 . A plot of the potential of mean force of the ligand in bulk solution and in the protein binding site shows that the ligand adopts a broader range of conformations in solution than when in the protein binding site, Figure 4 (a). The potential of mean force is calculated as a function of the root-mean-square deviation relative to a reference bound state structure. The reference structure was chosen from an equilibrated MD simulation of the ligandbound X-ray crystallographic structure. (a)

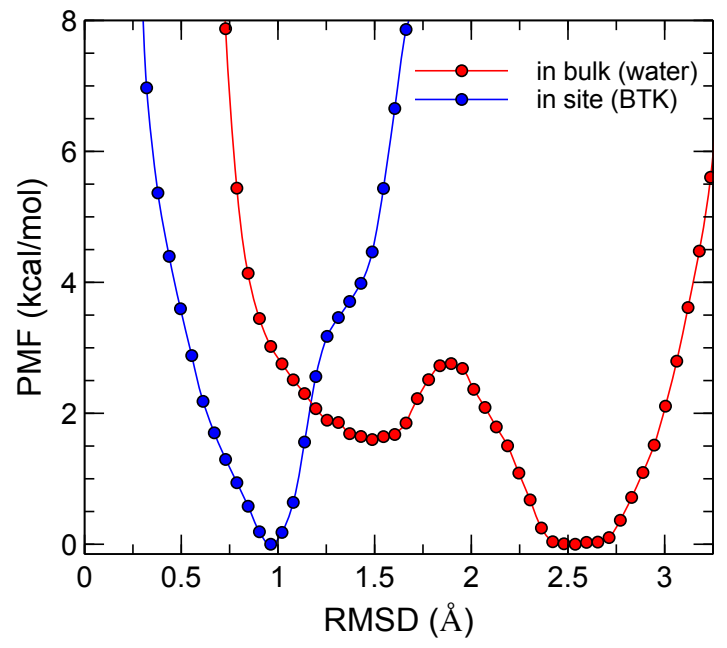

(b)

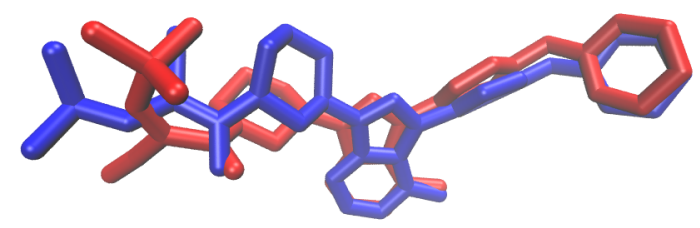

Figure 4. (a) Calculated potential of mean force (PMF) of the cyanoacrylamide ligand conformational degrees of freedom as a function of the root-mean-square deviation (RMSD) in bulk solution (water) and in the protein kinase binding site (BTK). (b) Sample conformational states taken up by the cyanoacrylamide ligand in bulk water and in BTK protein binding site. The red and blue structures represent the average conformational states adopted by the ligand in bulk water and in the protein binding site at RMSDs of $2.5 \AA$ and $1.0 \AA$, respectively, relative to average reference boundstate structure. The ligand adopts a significantly different conformation in solution and in the bound state.

In solution, the ligand preferentially holds a structure that is significantly different from the bound-state structure. This conformation has an RMSD with respect to the bound conformation of approximately $2.5 \AA$. When the ligand is confined to the binding site, this secondary conformation is highly unstable, and the ligand is restricted to remain close to its crystallographic conformation ( $\mathrm{RMSD} \cong 1.0 \AA)$. The ligand also adopts a higher energy structure in solution at $\mathrm{RMSD}$ of $\cong 1.5 \AA$. This structure occurs at a local minimum that is $\sim 2 \mathrm{kcal} / \mathrm{mol}$ higher on the PMF relative to the boundstate ligand conformation. The PMF of the ligand in bulk solution is also broader than in the protein binding site, which results from alternative ligand conformations being available to the ligand in bulk solution but not when bound to the protein. Collectively, these PMFs quantify the loss in conformational entropy of the cyanoacrylamide ligand upon binding to BTK. Figure 4 (b) shows the average conformation of the cyanoacrylamide ligand in bulk solution (red) and in the protein binding site (blue) at RMSDs of $2.5 \AA$ and $1.0 \AA$, respectively.

\section{Translational and Rotational Energies}

The free energy cost arising from restrictions in translational and rotational motions of the ligand upon binding $\left(\Delta \Delta G_{t+r}^{b u l k \rightarrow \text { site }}\right)$ is 15.3 $\mathrm{kcal} / \mathrm{mol}$, Table 1 . This suggests that the loss of ligand translational 
and rotational freedom upon binding results in a considerable free energy penalty.

\section{Non-Covalent Interaction Energy}

The interaction free energy $\left(\Delta \Delta G_{\text {int }}^{\text {bulk } \rightarrow \text { site }}\right)$ corresponds to the difference in intermolecular interactions between the ligand and bulk solution in comparison to its intermolecular interactions in the protein binding site. This term is the largest component of $\Delta \mathrm{G}_{\text {non-covalent, }}^{\circ}$ favoring ligand binding by $-31.1 \pm 1.4 \mathrm{kcal} / \mathrm{mol}$ (Table 1 ). Among the three major contributions to the nonbonding interaction energy, the dispersion component is the most dominant $\left(\Delta \Delta G_{\text {dis }}=-31.9\right.$ $\mathrm{kcal} / \mathrm{mol})$. This is followed by the electrostatic interactions $\left(\Delta \Delta G_{\text {elec }}=-5.9 \mathrm{kcal} / \mathrm{mol}\right)$, which is less than one-fifth the magnitude of the dispersion forces. The repulsive contribution opposes the binding of the ligand to the protein $\left(\Delta \Delta G_{r e p}=6.7 \mathrm{kcal} / \mathrm{mol}\right)$.

These results suggest that the contribution from the dispersion forces play a major role in the non-covalent binding interactions of the cyanoacrylamide ligand to BTK receptor. More specifically, the ligand enjoys more favorable dispersive interactions in the binding pocket of the protein kinase enzyme than in bulk solution. Examination of the structure of the protein-ligand complex shows that the phenol and piperidine moieties of the ligand are in close contact with hydrophobic side chains in the protein binding pocket (Figure 6), including Phe540, Leu528, and Met449. Hydrogen bonding interactions also contribute to enhancing the non-covalent interactions of the ligand in the binding pocket. One such example is the interaction between the backbone amide hydrogen of Met477 in the protein and a nitrogen in the pyrazolopyrimidine scaffold of the ligand.

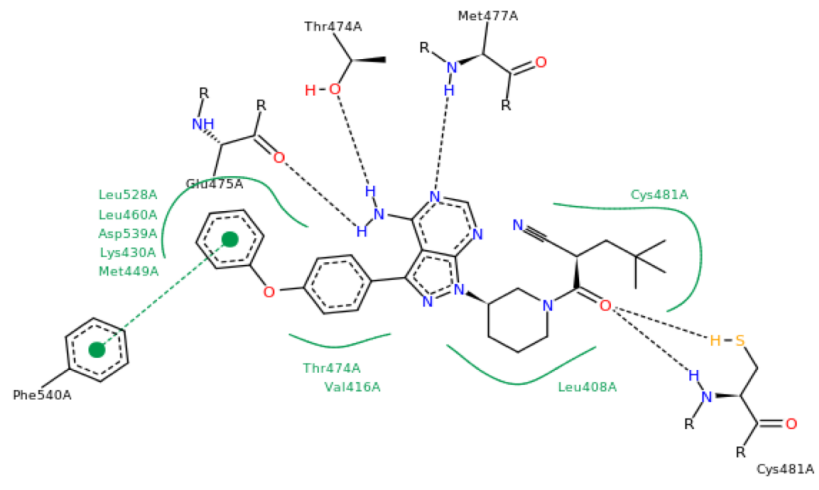

Figure 6. Ligand interaction diagram of t-butyl cyanoacrylamide ligand with amino acid residues of BTK (PDB ID: 4YHF). Hydrogen bonding, hydrophobic, and $\pi-\pi$ interactions are indicated by dashed black, solid green, and dashed green lines, respectively.

These attractive protein-ligand electrostatic interactions are countered by repulsive interactions, which includes the thermodynamic cost of expelling water molecules from the binding pockets and the rearrangement of the binding site to accommodate binding of the ligand $\left(\Delta \Delta G_{\text {repul }}=6.7 \mathrm{kcal} / \mathrm{mol}\right)$. The free energy of ligand binding to BTK is dominated by van der Waals dispersion interactions, which reflects a key role of dispersion forces in ligand-protein association. The relative magnitude of these components is consistent with the work of Roux and coworkers, ${ }^{24-26}$ who showed that van der Waals dispersion interactions is primarily responsible for the binding affinity and specificity of the anticancer drug imatinib to tyrosine kinases.

\section{Covalent Binding Free Energy Contribution}

The PMF for the addition reaction of the cyanoacrylamide ligand to BTK was calculated using QM/MM MD umbrella sampling simulations, Figure 7. The equilibrium non-covalent protein-ligand complex forms an intermolecular contact pair at an $\mathrm{r}_{\mathrm{C}_{\beta}-\mathrm{S}}$ distance of approximately $4.4 \AA$. This complex is used as a reference point for the $\mathrm{PMF}$, so its free energy is defined as $0 \mathrm{kcal} / \mathrm{mol}$. Relative to this noncovalent protein-ligand complex, the enolate intermediate is 16.1 $\mathrm{kcal} / \mathrm{mol}$ more stable. There is a small Gibbs energy barrier for the chemical reaction leading to the formation of the enolate intermediate complex, with a maximum of $3.4 \mathrm{kcal} / \mathrm{mol}$ at $\mathrm{r}_{\mathrm{C}_{\beta}-\mathrm{S}}=3.15 \AA$. The minimum for the PMF which corresponds to the enolate intermediate is observed at a $\mathrm{C}_{\beta}-\mathrm{S}$ distance of $1.85 \AA$. This distance is slightly more elongated than the typical $\mathrm{C}-\mathrm{S}$ bond length of approximately 1.80 Å because it is an intermediate state structure.

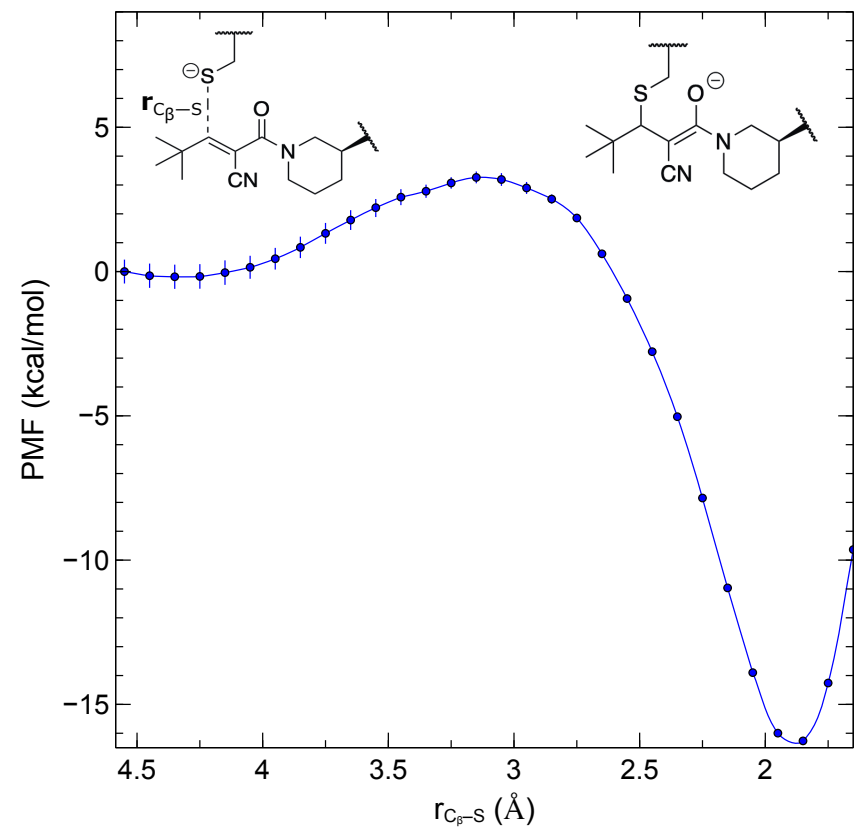

Figure 7. PMF for the addition reaction of t-butyl cyanoacrylamide ligand with Cys481 thiolate side chain of BTK in aqueous solution. The PMF was calculated using QM/MM MD umbrella sampling simulations (QM: $\omega$ B97X-D3BJ/def2-TZVP, MM: CHARMM36). The statistical uncertainty in the computed free energies were estimated by bootstrap error analysis.

To calculate the Gibbs energy for the reaction leading to the formation of the covalent adduct, we performed ONIOM QM/MM calculations to compute the energy of the final thioether product, using the non-covalent thiol complex as the reference state. From our ONIOM model, the computed free energy difference between the non-covalent thiol complex and the final thioether product of the chemical reaction was calculated to be $23.3 \mathrm{kcal} / \mathrm{mol}$ in favor of the thioether adduct. The binding free energy of the non-covalent thiol complex was calculated to be $-7.4 \pm 0.7 \mathrm{kcal} / \mathrm{mol}$ (see Supporting Information). As a result, the total binding free energy of the cyanoacrylamide ligand to BTK from its unbound state to its covalently modified ligand-bound state is $-30.7 \mathrm{kcal} / \mathrm{mol}$, with -19.3 $\mathrm{kcal} / \mathrm{mol}$ arising from the covalent binding free energy contribution. 
This indicates that the formation of the thioether linkage increases the binding free energy of the ligand beyond the typical affinities observed for non-covalent inhibitors by a large margin.

Free Energy Profile of Covalent Modification: Figure 8 illustrates the full free energy profile for the covalent binding of the cyanoacrylamide ligand to BTK combined from the individual components described above. The final covalently bound state has a total binding energy $\left(\Delta \mathrm{G}^{\circ}{ }_{\text {binding }}\right)$ of $-30.7 \mathrm{kcal} / \mathrm{mol}$. This reaction consists of multiple steps involving the target cysteine residue and the ligand. The first step in the reaction involves the deprotonation of the thiol side chain of Cys481 in BTK. The deprotonation Gibbs energy of Cys481 in BTK is estimated from its calculated $\mathrm{pK}_{\mathrm{a}}$ value of $9.4 \pm 0.2$, equivalent to a deprotonation Gibbs energy of $1.0 \pm 0.2$ $\mathrm{kcal} / \mathrm{mol}$ at $298.15 \mathrm{~K}$.

The formation of the noncovalent complex is significantly exergonic $(-11.4 \mathrm{kcal} / \mathrm{mol})$ and is consistent with the experimental binding energies between a similar non-covalent inhibitor and BTK. This indicates that non-covalent interactions still contribute a significant component to the binding affinity of a covalent-binding drug. ${ }^{65}$
The final step involves a chemical reaction between the thiolate group of Cys481 of the target protein and the electrophilic cyanoacrylamide warhead of the ligand. This reaction step leads to the formation of an enolate intermediate, which is then protonated to form the final thioether covalent adduct. The activation energy required for this chemical addition step is modest $\left(\Delta \mathrm{G}_{\text {binding }}^{T S}=3.4 \pm\right.$ $0.3 \mathrm{kcal} / \mathrm{mol}$ ). The enolate intermediate formed from this chemical reaction is $\approx 16.1 \mathrm{kcal} / \mathrm{mol}$ more stable than the non-covalent state and has an absolute Gibbs energy (i.e., $\Delta \mathrm{G}_{\text {enolate }}$ ) of -27.5 $\mathrm{kcal} / \mathrm{mol}$. The final covalent complex is approximately $3.2 \mathrm{kcal} / \mathrm{mol}$ more stable than the enolate intermediate. In combination, the total binding energy resulting from the addition reaction of BTK with the $\mathrm{t}$-butyl cyanoacrylamide ligand is predicted to be approximately -30 $\mathrm{kcal} / \mathrm{mol}$, with $\approx-19 \mathrm{kcal} / \mathrm{mol}$ arising from the covalent binding energy contribution and $\approx-11 \mathrm{kcal} / \mathrm{mol}$ arising from the non-covalent binding energy contribution. As only a small fraction of human kinase proteins possess a cysteine residue in this location, covalent inhibitors that possess a corresponding electrophilic group have an extra level of selectivity for this target, a phenomenon that is not observed with inhibitors that solely bind non-covalently to their targets.

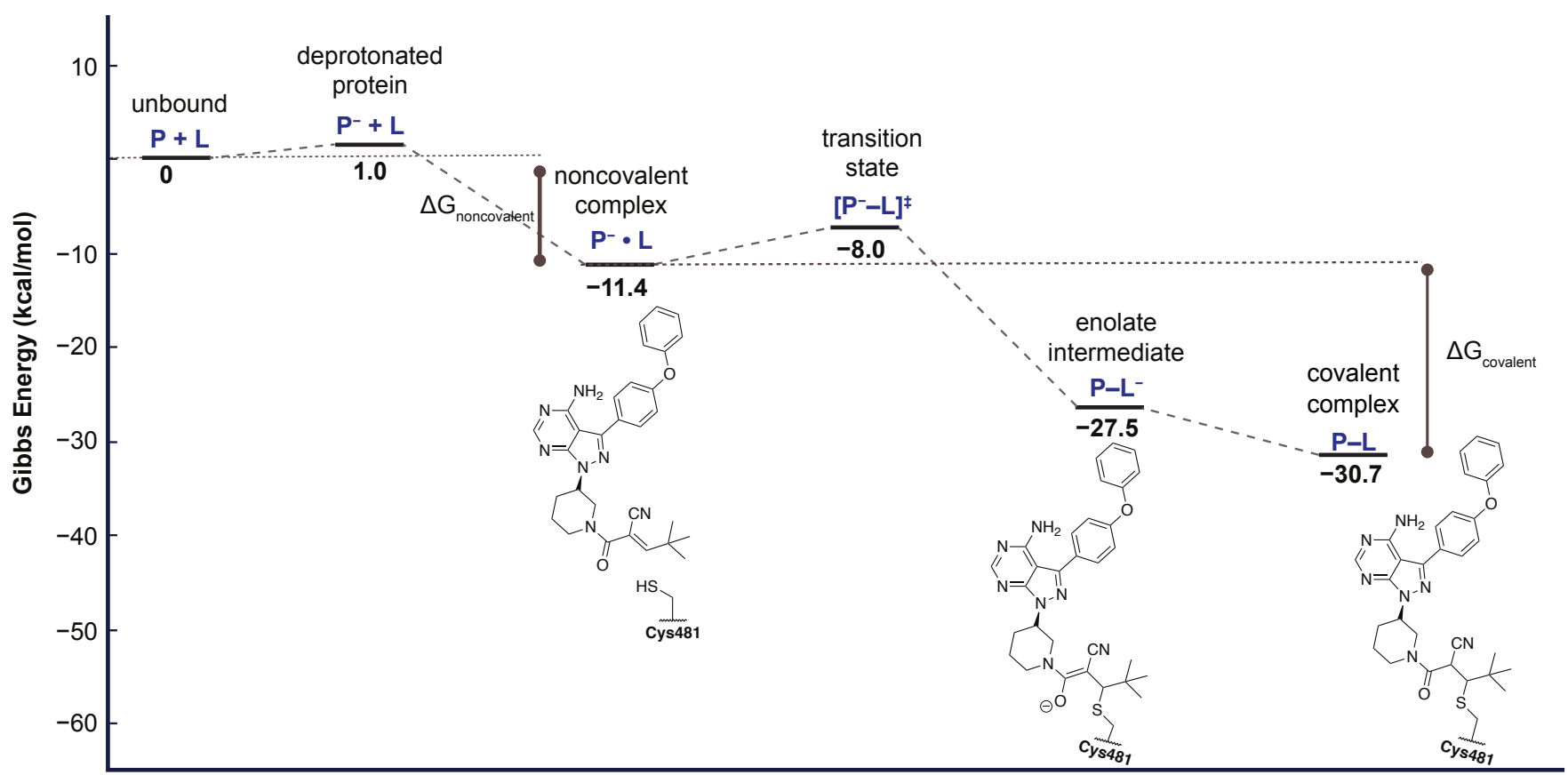

Figure 8. Free energy profile of covalent modification of Cys481 in BTK (P) by a cyanoacrylamide inhibitor (L).

\section{Conclusion}

In summary, we have employed combined molecular dynamics simulation methods and high-level QM/MM calculations to model all the steps involved in the covalent modification of a druggable cysteine residue (Cys481) in the cancer target BTK. We achieved this by modeling the addition reaction of Cys481 of BTK to a t-butyl cyanoacrylamide Targeted Covalent Inhibitor. From our modeling approach, we were able to calculate the total covalent and non-covalent binding energies of the reaction. A rigorous, complete free energy profile of the chemical reaction was also calculated. In our model, the complete calculation of the binding free energy of the ligand to Cys481 of BTK consisted of three steps: namely, the deprotonation of the active site cysteine residue to form a reactive thiolate, conventional non-covalent protein-ligand binding of the enzyme and inhibitor, and a two-step Michael addition reaction between the nucleophilic cysteine side chain of the enzyme target and the electrophilic warhead of the ligand. Our results indicate that both covalent and non-covalent binding interactions are significant to the binding affinity of the inhibitor to its target. The deprotonation of the cysteine thiol group and the activation energy for the formation of the enolate intermediate present modest barriers to the covalent binding that are not present in non-covalent binding. The formation of the chemical bond step yields a free energy of $\approx-19 \mathrm{kcal} / \mathrm{mol}$ relative to the non-covalent binding energy contribution of $\approx-11$ $\mathrm{kcal} / \mathrm{mol}$. Van der Waals dispersion interactions between the ligand and individual amino acid residues in the protein binding pocket are the largest component of the non-covalent binding energy, strongly 
favoring ligand binding. The covalent binding step constitutes a large component of the total binding free energy, which suggests a significantly exergonic chemical reaction for this warhead. Continued maturation of these models will allow computer modeling to contribute to the development of new covalent modifier drugs in the same way they have helped refine the affinity and selectivity of noncovalent drugs.

\section{ASSOCIATED CONTENT}

\section{Supporting Information}

Computational details and specific input keywords used in the configuration files of molecular dynamics simulations, binding free energy calculation details, constant-pH molecular dynamics simulation details, $\mathrm{t}$ butyl cyanoacrylamide ligand charges and atom types (PDF). The Supporting Information is available free of charge on the ACS Publications website.

\section{AUTHOR INFORMATION}

\section{Corresponding Author}

*E-mail: esaw83@mun.ca, Christopher.Rowley@carleton.ca

Phone: +1 (709) 864-2229

\section{Author Contributions}

E.A-W performed the simulations and was the primary contributor to the manuscript. C.N.R. was a secondary contributor to writing the manuscript. All authors have given approval to the final version of the manuscript.

\section{Notes}

The authors declare no competing financial interest.

\section{ACKNOWLEDGMENT}

The authors thank NSERC of Canada for funding through the Discovery Grant program (Application 418505-2012). E.A-W. thanks the government of Canada (Vanier Canada Graduate Scholarship) and the School of Graduate Studies at Memorial University for a graduate fellowship. E.A-W also thanks ACEnet for an Advanced Research Computing Fellowship. Computational resources were provided by Compute Canada (RAP: djk-615-ab) through the SHARCNet consortia. Additional computational resources were provided by the Center for Health Informatics and Analytics (CHIA) of the Faculty of Medicine at Memorial University of Newfoundland.

\section{REFERENCES}

(1) Potashman, M. H.; Duggan, M. E. Covalent Modifiers: An Orthogonal Approach to Drug Design. J. Med. Chem. 2009, 52 (5), 1231-1246.

(2) Singh, J.; Petter, R. C.; Baillie, T. A.; Whitty, A. The Resurgence of Covalent Drugs. Nat. Rev. Drug Discov. 2011, 10 (4), 307-317.

(3) Baillie, T. A. Targeted Covalent Inhibitors for Drug Design. Angew. Chemie - Int. Ed. 2016, 55 (43), 13408-13421.

(4) Vasudevan, A.; Argiriadi, M. A.; Baranczak, A.; Friedman, M. M.; Gavrilyuk, J.; Hobson, A. D.; Hulce, J. J.; Osman, S.; Wilson, N. S. Covalent Binders in Drug Discovery. In Progress in Medicinal Chemistry; Elsevier B.V., 2019; Vol. 58, pp 1-62.

(5) Singh, J.; Petter, R. C.; Kluge, A. F. Targeted Covalent Drugs of the Kinase Family. Curr. Opin. Chem. Biol. 2010, 14 (4), 475-480.

(6) Berndt, N.; Karim, R. M.; Schönbrunn, E. Advances of Small Molecule Targeting of Kinases. Curr. Opin. Chem. Biol. 2017, 39, 126-132.

(7) Ferguson, F. M.; Gray, N. S. Kinase Inhibitors: The Road Ahead. Nat. Rev. Drug Discov. 2018, 17(5), 353-377.

(8) Joshi, M.; Rizvi, S. M.; Belani, C. P. Afatinib for the Treatment of Metastatic Non-Small Cell Lung Cancer. Cancer Manag. Res. 2015, 7, $75-82$.

(9) Byrd, J. C.; Furman, R. R.; Coutre, S. E.; Flinn, I. W.; Burger, J. A.;
Blum, K. A.; Grant, B.; Sharman, J. P.; Coleman, M.; Wierda, W. G.; et al. Targeting BTK with Ibrutinib in Relapsed Chronic Lymphocytic Leukemia. N. Engl.J. Med. 2013, 369 (1), 32-42.

(10) Bauer, R. A. Covalent Inhibitors in Drug Discovery: From Accidental Discoveries to Avoided Liabilities and Designed Therapies. Drug Discov. Today 2015, 20(9), 1061-1073.

(11) Shannon, D. A.; Weerapana, E. Covalent Protein Modification: The Current Landscape of Residue-Specific Electrophiles. Curr. Opin. Chem. Biol. 2015, 24, 18-26.

(12) Thurlkill, R. L.; Grimsley, G. R.; Scholtz, J. M.; Pace, C. N. PK Values of the Ionizable Groups of Proteins. Protein Sci. 2006, 15 (5), 12141218.

(13) Liu, Q.; Sabnis, Y.; Zhao, Z.; Zhang, T.; Buhrlage, S. J.; Jones, L. H.; Gray, N. S. Developing Irreversible Inhibitors of the Protein Kinase Cysteinome. Chem. Biol. 2013, 20(2), 146-159.

(14) Chaikuad, A.; Koch, P.; Laufer, S. A.; Knapp, S. The Cysteinome of Protein Kinases as a Target in Drug Development. Angew. Chemie Int. Ed. 2018, 57(16), 4372-4385.

(15) Cohen, P. Protein Kinases--the Major Drug Targets of the TwentyFirst Century? Nat. Rev. Drug Discov. 2002, 1 (April), 309-315.

(16) Abdeldayem, A.; Raouf, Y. S.; Constantinescu, S. N.; Moriggl, R.; Gunning, P. T. Advances in Covalent Kinase Inhibitors. Chem. Soc. Rev. 2020, 49(9), 2617-2687.

(17) Gehringer, M.; Laufer, S. A. Emerging and Re-Emerging Warheads for Targeted Covalent Inhibitors: Applications in Medicinal Chemistry and Chemical Biology. J. Med. Chem. 2019, 62 (12), 5673-5724.

(18) Jackson, P. A.; Widen, J. C.; Harki, D. A.; Brummond, K. M. Covalent Modifiers: A Chemical Perspective on the Reactivity of $\alpha, \beta$ Unsaturated Carbonyls with Thiols via Hetero-Michael Addition Reactions. J. Med. Chem. 2017, 60(3), 839-885.

(19) Nair, D. P.; Podgórski, M.; Chatani, S.; Gong, T.; Xi, W.; Fenoli, C. R.; Bowman, C. N. The Thiol-Michael Addition Click Reaction: A Powerful and Widely Used Tool in Materials Chemistry. Chem. Mater. 2014, 26(1), 724-744.

(20) Awoonor-Williams, E.; Rowley, C. N. How Reactive Are Druggable Cysteines in Protein Kinases? J. Chem. Inf. Model. 2018, 58 (9), 1935-1946.

(21) Serafimova, I. M.; Pufall, M. A.; Krishnan, S.; Duda, K.; Cohen, M. S.; Maglathlin, R. L.; McFarland, J. M.; Miller, R. M.; Frödin, M.; Taunton, J. Reversible Targeting of Noncatalytic Cysteines with Chemically Tuned Electrophiles. Nat. Chem. Biol. 2012, 8(5), 471476.

(22) Miller, R. M.; Paavilainen, V. O.; Krishnan, S.; Serafimova, I. M.; Taunton, J. Electrophilic Fragment-Based Design of Reversible Covalent Kinase Inhibitors. J. Am. Chem. Soc. 2013, 135 (14), 52985301.

(23) Bradshaw, J. M.; McFarland, J. M.; Paavilainen, V. O.; Bisconte, A.; Tam, D.; Phan, V. T.; Romanov, S.; Finkle, D.; Shu, J.; Patel, V.; et al. Prolonged and Tunable Residence Time Using Reversible Covalent Kinase Inhibitors. Nat. Chem. Biol. 2015, 11 (7), 525-531.

(24) Lin, Y.-L.; Meng, Y.; Jiang, W.; Roux, B. Explaining Why Gleevec Is a Specific and Potent Inhibitor of Abl Kinase. Proc. Natl. Acad. Sci. U. S. A. 2013, 110 (5), 1664-1669.

(25) Lin, Y. L.; Roux, B. Computational Analysis of the Binding Specificity of Gleevec to Abl, c-Kit, Lck, and c-Src Tyrosine Kinases. J. Am. Chem. Soc. 2013, 135 (39), 14741-14753.

(26) Lin, Y. L.; Meng, Y.; Huang, L.; Roux, B. Computational Study of Gleevec and G6G Reveals Molecular Determinants of Kinase Inhibitor Selectivity. J. Am. Chem. Soc. 2014, 136 (42), 1475314762 .

(27) Wang, L.; Wu, Y.; Deng, Y.; Kim, B.; Pierce, L.; Krilov, G.; Lupyan, D.; Robinson, S.; Dahlgren, M. K.; Greenwood, J.; et al. Accurate and Reliable Prediction of Relative Ligand Binding Potency in Prospective Drug Discovery by Way of a Modern Free-Energy Calculation Protocol and Force Field. J. Am. Chem. Soc. 2015, 137 (7), 26952703.

(28) Alsamarah, A.; LaCuran, A. E.; Oelschlaeger, P.; Hao, J.; Luo, Y. Uncovering Molecular Bases Underlying Bone Morphogenetic Protein Receptor Inhibitor Selectivity. PLoS One 2015, 1O (7), 1-20. Aldeghi, M.; Heifetz, A.; Bodkin, M. J.; Knapp, S.; Biggin, P. C. Accurate Calculation of the Absolute Free Energy of Binding for Drug Molecules. Chem. Sci. 2016, 7(1), 207-218. 
(30) Aldeghi, M.; Heifetz, A.; Bodkin, M. J.; Knapp, S.; Biggin, P. C. Predictions of Ligand Selectivity from Absolute Binding Free Energy Calculations. J. Am. Chem. Soc. 2017, 139(2), 946-957.

(31) Chatterjee, P.; Botello-Smith, W. M.; Zhang, H.; Qian, L.; Alsamarah, A.; Kent, D.; Lacroix, J. J.; Baudry, M.; Luo, Y. Can Relative Binding Free Energy Predict Selectivity of Reversible Covalent Inhibitors? J. Am. Chem. Soc. 2017, 139 (49), 17945-17952.

(32) Moraca, F.; Negri, A.; De Oliveira, C.; Abel, R. Application of Free Energy Perturbation (FEP+) to Understanding Ligand Selectivity: A Case Study to Assess Selectivity between Pairs of Phosphodiesterases (PDE's). J. Chem. Inf. Model. 2019, 59, 2729-2740.

(33) Awoonor-Williams, E.; Walsh, A. G.; Rowley, C. N. Modeling Covalent-Modifier Drugs. Biochim. Biophys. Acta - Proteins Proteomics 2017, 1865 (11), 1664-1675.

(34) Awoonor-Williams, E.; Isley, W. C.; Dale, S. G.; Johnson, E. R.; Yu, H.; Becke, A. D.; Roux, B.; Rowley, C. N. Quantum Chemical Methods for Modeling Covalent Modification of Biological Thiols. J. Comput. Chem. 2020, 41 (5), 427-438.

(35) Krishnan, S.; Miller, R. M.; Tian, B.; Mullins, R. D.; Jacobson, M. P.; Taunton, J. Design of Reversible, Cysteine-Targeted Michael Acceptors Guided by Kinetic and Computational Analysis. J. Am. Chem. Soc. 2014, 136(36), 12624-12630.

(36) Krenske, E. H.; Petter, R. C.; Houk, K. N. Kinetics and Thermodynamics of Reversible Thiol Additions to Mono- and Diactivated Michael Acceptors: Implications for the Design of Drugs That Bind Covalently to Cysteines. J. Org. Chem. 2016, 81 (23), 11726-11733.

(37) Yu, H. S.; Gao, C.; Lupyan, D.; Wu, Y.; Kimura, T.; Wu, C.; Jacobson, L.; Harder, E.; Abel, R.; Wang, L. Toward Atomistic Modeling of Irreversible Covalent Inhibitor Binding Kinetics. J. Chem. Inf. Model. 2019, 59(9), 3955-3967.

(38) Wang, J.; Deng, Y.; Roux, B. Absolute Binding Free Energy Calculations Using Molecular Dynamics Simulations with Restraining Potentials. Biophys.J. 2006, 91 (8), 2798-2814.

(39) Chung, L. W.; Sameera, W. M. C.; Ramozzi, R.; Page, A. J.; Hatanaka, M.; Petrova, G. P.; Harris, T. V.; Li, X.; Ke, Z.; Liu, F.; et al. The ONIOM Method and Its Applications. Chem. Rev. 2015, 115 (12), 5678-5796.

(40) Jorgensen, W. L.; Chandrasekhar, J.; Madura, J. D.; Impey, R. W.; Klein, M. L. Comparison of Simple Potential Functions for Simulating Liquid Water. J. Chem. Phys. 1983, 79 (2), 926.

(41) Huang, L.; Roux, B. Automated Force Field Parameterization for Nonpolarizable and Polarizable Atomic Models Based on Ab Initio Target Data. J. Chem. Theory Comput. 2013, 9 (8), 3543-3556.

(42) Vanommeslaeghe, K.; Hatcher, E.; Acharya, C.; Kundu, S.; Zhong, S.; Shim, J.; Darian, E.; Guvench, O.; Lopes, P.; Vorobyov, I.; et al. CHARMM General Force Field: A Force Field for Drug-like Molecules Compatible with the CHARMM All-Atom Additive Biological Force Fields. J. Comput. Chem. 2010, 31 (4), 671-690.

(43) Best, R. B.; Zhu, X.; Shim, J.; Lopes, P. E. M.; Mittal, J.; Feig, M.; MacKerell, A. D. Optimization of the Additive CHARMM All-Atom Protein Force Field Targeting Improved Sampling of the Backbone $\phi$, $\psi$ and Side-Chain $\chi 1$ and $\chi 2$ Dihedral Angles. J. Chem. Theory Comput. 2012, 8 (9), 3257-3273.

(44) Awoonor-Williams, E.; Rowley, C. N. The Hydration Structure of Methylthiolate from QM/MM Molecular Dynamics. J. Chem. Phys. 2018, 149 (4), 045103.

(45) Awoonor-Williams, E.; Rowley, C. N. Evaluation of Methods for the Calculation of the PKa of Cysteine Residues in Proteins. J. Chem. Theory Comput. 2016, 12 (9), 4662-4673.

(46) Phillips, J. C.; Braun, R.; Wang, W.; Gumbart, J.; Tajkhorshid, E.; Villa, E.; Chipot, C.; Skeel, R. D.; Kalé, L.; Schulten, K. Scalable Molecular Dynamics with NAMD. J. Comput. Chem. 2005, 26(16), 1781-1802.
Method for Ewald Sums in Large Systems. J. Chem. Phys. 1993, 98 (12), 10089.

(48) Essmann, U.; Perera, L.; Berkowitz, M. L.; Darden, T.; Lee, H.; Pedersen, L. G. A Smooth Particle Mesh Ewald Method. J. Chem. Phys. 1995, 103 (19), 8577-8593.

(49) Ryckaert, J.-P.; Ciccotti, G.; Berendsen, H. J. . Numerical Integration of the Cartesian Equations of Motion of a System with Constraints: Molecular Dynamics of n-Alkanes. J. Comput. Phys. 1977, 23 (3), 327-341.

(50) Woo, H. J.; Roux, B. Calculation of Absolute Protein-Ligand Binding Free Energy from Computer Simulations. Proc. Natl. Acad. Sci. U.S. A. 2005, 102 (19), 6825-6830.

(51) Deng, Y.; Roux, B. Calculation of Standard Binding Free Energies: Aromatic Molecules in the T4 Lysozyme L99A Mutant. J. Chem. Theory Comput. 2006, 2(5), 1255-1273.

(52) Deng, Y.; Roux, B. Computations of Standard Binding Free Energies with Molecular Dynamics Simulations. J. Phys. Chem. B 2009, 113 (8), 2234-2246.

(53) Grossfield, A. WHAM: The Weighted Histogram Analysis Method, Version 2.0.9. Rochester University, Rochester, NY, 2013.

(54) Weeks, J. D.; Chandler, D.; Andersen, H. C. Role of Repulsive Forces in Determining the Equilibrium Structure of Simple Liquids. J. Chem. Phys. 1971, 54 (12), 5237-5247.

(55) Deng, Y.; Roux, B. Hydration of Amino Acid Side Chains: Nonpolar and Electrostatic Contributions Calculated from Staged Molecular Dynamics Free Energy Simulations with Explicit Water Molecules. J. Phys. Chem. B2004, 108 (42), 16567-16576.

(56) Melo, M. C. R.; Bernardi, R. C.; Rudack, T.; Scheurer, M.; Riplinger, C.; Phillips, J. C.; Maia, J. D. C.; Rocha, G. B.; Ribeiro, J. V; Stone, J. E.; et al. NAMD Goes Quantum: An Integrative Suite for Hybrid Simulations. Nat. Methods 2018, 15 (5), 351-354.

(57) Neese, F. The ORCA Program System. Wiley Interdiscip. Rev. Comput. Mol. Sci. 2012, 2(1), 73-78.

(58) Neese, F. Software Update: The ORCA Program System, Version 4.0. Wiley Interdiscip. Rev. Comput. Mol. Sci. 2018, 8(1), e1327.

(59) Bakowies, D.; Thiel, W. Hybrid Models for Combined Quantum Mechanical and Molecular Mechanical Approaches. J. Phys. Chem. 1996, 100 (25), 10580-10594.

(60) Chai, J. Da; Head-Gordon, M. Long-Range Corrected Hybrid Density Functionals with Damped Atom-Atom Dispersion Corrections. Phys. Chem. Chem. Phys. 2008, 10 (44), 6615-6620.

(61) Grimme, S.; Ehrlich, S.; Goerigk, L. Effect of the Damping Function in Dispersion Corrected Density Functional Theory. J. Comput. Chem. 2011, 32 (7), 1456-1465.

(62) Smith, J. M.; Jami Alahmadi, Y.; Rowley, C. N. Range-Separated DFT Functionals Are Necessary to Model Thio-Michael Additions. J. Chem. Theory Comput. 2013, 9(11), 4860-4865.

(63) Frisch, M. J.; Trucks, G. W.; Schlegel, H. B.; Scuseria, G. E.; Robb, M. A.; Cheeseman, J. R.; Scalmani, G.; Barone, V.; Petersson, G. A.; Nakatsuji, H.; Li, X.; Caricato, M.; Marenich, A. V.; Bloino, J.; Janesko, B. G.; Gomperts, R.; Mennucci, B.; Hratch, D. J. Gaussian 16, Revision C.03. Gaussian Inc., Wallingford CT, 2016.

(64) Abraham, M. J.; Murtola, T.; Schulz, R.; Páll, S.; Smith, J. C.; Hess, B.; Lindahl, E. GROMACS: High Performance Molecular Simulations through Multi-Level Parallelism from Laptops to Supercomputers. SoftwareX2015, 1-2, 19-25.

(65) Schwartz, P. a; Kuzmic, P.; Solowiej, J.; Bergqvist, S.; Bolanos, B.; Almaden, C.; Nagata, A.; Ryan, K.; Feng, J.; Dalvie, D.; et al. Covalent EGFR Inhibitor Analysis Reveals Importance of Reversible Interactions to Potency and Mechanisms of Drug Resistance. Proc. Natl. Acad. Sci. U.S. A. 2014, 111 (1), 173-178. 


\section{For Table of Contents Use Only}

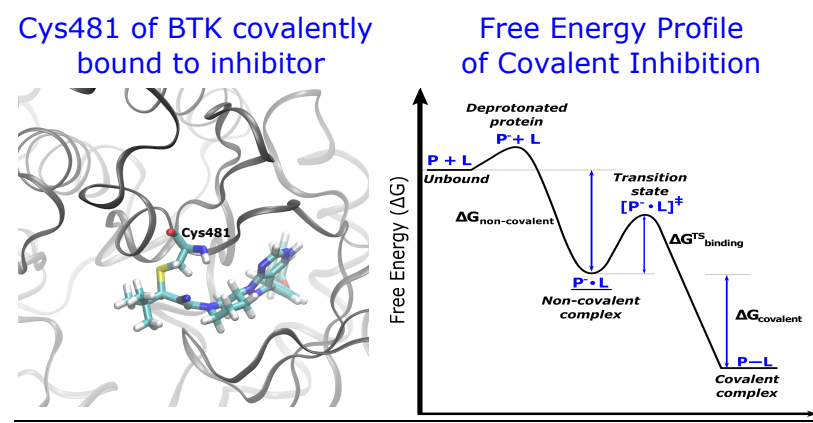

Calculating the Full Free Energy Profile for Covalent Modification of a Druggable Cysteine in Bruton's Tyrosine Kinase Ernest Awoonor Williams and Christopher N. Rowley 